\title{
Access to oral healthcare services of adolescents of a large-size municipality in northeastern Brazil
}

\author{
Andreza Cristina de Lima Targino \\ MASSONI(a) \\ Érika PORTO(a) \\ Luizy Raquel Barbosa Oliveira \\ FERREIRA $^{(a)}$ iD \\ Herdesson Pereira SILVA(a) iD \\ Monalisa da Nóbrega Cesarino \\ GOMES(a) \\ Matheus França PERAZZO(b) iD \\ Sérgio D'AVILA ${ }^{(a)}$ iD \\ Ana Flávia \\ GRANVILLE-GARCIA(a) \\ (a) Universidade Estadual da Paraíba - UEPB, \\ Center for Biological and Health Sciences, \\ Department of Dentistry, Campina Grande, \\ PB, Brazil. \\ (b) Universidade Federal de Minas Gerais - \\ UFMG, School of Dentistry, Department \\ of Pediatric Dentistry, Belo Horizonte, \\ MG, Brazil.
}

Declaration of Interests: The authors certify that they have no commercial or associative interest that represents a conflict of interest in connection with the manuscript.

Corresponding Author:

Andreza Cristina de Lima Targino Massoni E-mail: andrezatargino@gmail.com

ht1ps://doi.org/10.1590/1807-3107bor-2020.vol34.0029

Submitted: April 21, 2019

Accepted for publication: January 6, 2020

Last revision: January 31, 2020
Abstract: The aim of this study was to describe and evaluate access to oral health services among adolescents enrolled in public schools of Campina Grande, Paraíba, Brazil, a large-size municipality in the Northeast of Brazil. An observational, descriptive, analytical, quantitative, and cross-sectional study was carried out through a school survey, in which four validated questionnaires were applied to 438 adolescents aged 12 to 19 years. Data were processed using the SPSS statistical software version 20.0, with bivariate analysis and multivariate analysis through Poisson regression. About $90.9 \%$ of adolescents reported having visited the dentist at least once; however, when considering the last 6 months, this percentage fell to $48.4 \%$. Adolescents used private services $(50.2 \%)$ or the public service $(49.8 \%)$. About $70.6 \%$ of interviewees reported dental treatment (61.1\%) as the main reason for seeking the service. Through multivariate analysis, it was observed that the demand for the service was higher among female adolescents $(60.5 \%, \mathrm{p}<0.001)$; the other variables did not present statistically significant differences. In conclusion, the access to oral healthcare services reported by adolescents was good, but there is still a considerable part of this population with no access. Variables that presented significant associated with dental services were gender and toothache history, but only gender remained significant in the multivariate model.

Keywords: Health Services; Adolescent; Oral Health.

\section{Introduction}

Adolescence is an important developmental period, and the healthcare decisions made in this phase can reflect in the health and lifestyle at adulthood. Although adolescents experience the highest levels of well-being compared to the other life cycles, adolescents may not have the best oral health status. ${ }^{1,2,3}$ Inadequate oral conditions in this age group go beyond functional limitation and negatively impact social, psychological, and esthetic domains. ${ }^{4,5}$ Therefore, as oral health has a strong influence on the quality of life, understanding the complex situation of adolescents' oral condition is a challenge for dentists. ${ }^{6}$

The term "access" is discussed in the literature as part of the process of providing integral healthcare. Access involves the continuous and 
organized provision of healthcare services that people can use at a certain time and place. ${ }^{7}$ Moreover, access to healthcare services is allied to socially determined fundamental human rights, including peace, security, housing, freedom, education, healthy eating, employment, and income. ${ }^{7,8}$

Some justifications for the non-adherence to dental treatment among adolescents were identified by Vazquez et al., ${ }^{9}$ among them, priority, attributed to situations in which dental treatment is not seen as urgent or important, neglect, lack of time, fear, difficulty of access, and fear of pain. Etiological factors related to fear of dental treatment include previous negative experiences with treatment, lack of information on the procedure to be carried out, anesthesia needle, high speed dental motors, and having had dental extractions. The delay in seeking the dentist for fear or fear of pain is harmful to health and ends up reinforcing this feeling. In addition, avoiding the dentist favors the evolution of the severity of an eventually simple oral problem.,10,11

Another factor that influences adolescents' decision to seek dental services is anxiety, which causes a significant impact on oral health, causing the patient to postpone the visit to the dentist and frequently increasing dental problems. In this cycle, when the decision to seek dental care occurs, most of the time, treatment is much more invasive. ${ }^{12}$

Regarding the use of dental services, Teixeira, Roncalli and $\mathrm{Noro}^{13}$ observed that the last dental consultation and participation in collective oral health actions during adolescence were associated with a higher incidence of dental caries. Thus, the main reason to visit a dentist in all age groups was pain or treatment, demonstrating that most people who seek dental services are those who have some need; i.e., visiting the dentist in the last twelve months in adolescence is associated with people requiring treatment. The absence of toothache prevents individuals to seek dental care as a priority, thus, they end up by neglecting oral health. ${ }^{14}$

Considering the above, this study aimed to describe and evaluate the access to oral healthcare services of adolescents enrolled in the public education network of a large-size municipality in Northeastern Brazil.

\section{Methodology}

An observational, descriptive, quantitative, analytical, cross-sectional study was carried out based on a survey conducted in public schools of Campina Grande, a large-size municipality with Human Development Index (HDI) of 0.720, located $112 \mathrm{~km}$ from the State Capital, João Pessoa. ${ }^{12}$

The population of this study consisted of 29,838 adolescents aged 12 to 19 years enrolled in public schools. For sample size determination, a formula was used considering: finite population of 29,838 adolescents, acceptable error of 5.0\%, confidence level of $95 \%$, and prevalence of $50.0 \%$ (previously unknown prevalence of the phenomenon). A sample size of 380 students was obtained, to which a $20 \%$ was added to cover for possible losses (76 adolescents). ${ }^{15}$ Thus, the final sample was between 380 and 456 volunteers distributed in a stratified manner in the 8 Health Districts of Campina Grande. Firstly, public schools were randomly selected maintaining the proportions within the different districts using the Microsoft Excel program (Microsoft Corp., version 2003, USA). Secondly, the selection of adolescents for the sample was based on a simple randomization procedure.

Data collection was done through the application of a questionnaire, which sought to evaluate the use of oral healthcare services and the seeking of dental care by adolescents. The questionnaire was based on the survey adopted in the National Survey on Household Sampling (PNAD). ${ }^{16}$ Another three questionnaires related to the evaluation of dental fear, ${ }^{17}$ dental anxiety, ${ }_{1}^{18}$ and toothache ${ }^{19}$ were also used. Variables related to gender and age of participants were also collected.

Prior to the application of questionnaires, parents or guardians authorized the adolescents' participation through signing the Informed Consent Form. For personal authorization, a specific Assent Form was issued for adolescents.

Inclusion criteria were adolescents aged 12-19 years enrolled in public schools who agreed to participate in the study and were authorized by parents or guardians. Adolescents with mental, sensory, and behavioral disorders and those under 18 years of age who had participation prohibited by parents were 
excluded from the study, as well as those who chose not to participate in the study.

For statistical analyses, data were categorized into two groups according to age (12-14 years and 15-19 years) and gender (male and female). Data were processed in the Statistical Package for Social Science (SPSS) version 20.0. Descriptive analysis was carried out to verify the frequency of access to dental care as well as its characteristics (history of visits to the dentist, place of service, first visit, dental health plan, evaluation of care, and reason for the last visit).

Bivariate and multivariate analysis were performed through Poisson's regression to verify the relationship between access to oral healthcare services in the last 6 months and associated factors (gender, age, history of toothache, anxiety, and fear) among adolescents. Variables with $\mathrm{p}<0.20$ in the bivariate model were inserted into the multivariate regression model by means of backward elimination. In the final model, variables with $\mathrm{p}<0.05$ were considered to be associated. In all tests, $5 \%$ significance level was adopted. The model goodness of fit test showed deviance of 241,65 and Pearson Chi-square of 189,344 ( $\mathrm{df}=353)$. Overdispersion was not a problem for this dataset.

This study was submitted to the Ethics Research Committee of the State University of Paraíba for approval (Protocol No. 51497715.4.0000.5187). The study followed the ethical principles proposed in Resolution 466/2012 of the National Health Council, guaranteeing the secrecy of data concerning participants.

\section{Results}

At the end of data collection, 438 adolescents responded to the questionnaire regarding access to oral health services. Most of the participants were females $(50.9 \%)$, between 15 to 19 years old $(67.4 \%)$, and with history of some toothache in life $(67.9 \%)$, although the toothache experience was lower in the last 6 months (29.8\%). Almost all participants reported dental anxiety (88.4\%) and dental fear (91.0\%). Although $63 \%$ of participants reported having sought some health service in the last 6 months, $48.4 \%$ visited the dentist in this same period (Table 1).

According to Table 1, there was a balance about type of care; $50.2 \%$ of adolescents reported having used the private service and $49.8 \%$ the public service, and a minority $(22.1 \%)$ used dental health insurance. Among participants, $70.6 \%$ received care at the first visit, emphasizing that the reason for consultation was predominantly for treatment (61.1\%).

Table 1. Frequency of access to health services and their characteristics among adolescents in public schools. Campina Grande, Brazil.

\begin{tabular}{|c|c|}
\hline Variables & Frequency (\%) \\
\hline \multicolumn{2}{|l|}{ Gender } \\
\hline Female & 223(50.9) \\
\hline Male & $215(49.1)$ \\
\hline \multicolumn{2}{|l|}{ Age group (years) } \\
\hline $12-14$ & $143(32.6)$ \\
\hline $15-19$ & $295(67.4)$ \\
\hline \multicolumn{2}{|c|}{ History of toothache in life } \\
\hline Yes & $283(67.9)$ \\
\hline No & $134(32.1)$ \\
\hline \multicolumn{2}{|c|}{ History of toothache in the last 6 months } \\
\hline Yes & $122(29.8)$ \\
\hline No & $288(70.2)$ \\
\hline \multicolumn{2}{|l|}{ Anxiety } \\
\hline Yes & $352(88.4)$ \\
\hline No & $46(11.6)$ \\
\hline \multicolumn{2}{|l|}{ Fear } \\
\hline Yes & $362(91.0)$ \\
\hline No & $36(9.0)$ \\
\hline \multicolumn{2}{|c|}{ History of the visit to the health service in the last 6 months } \\
\hline No & $162(37.0)$ \\
\hline Yes & $276(63.0)$ \\
\hline \multicolumn{2}{|c|}{ It went to the dentist } \\
\hline No & $40(9.1)$ \\
\hline Yes & $398(90.9)$ \\
\hline \multicolumn{2}{|c|}{ Visit to the dentist in the last 6 months } \\
\hline No & $226(51.6)$ \\
\hline Yes & $212(48.4)$ \\
\hline \multicolumn{2}{|c|}{ Got dental care on the first visit } \\
\hline No & $117(29.4)$ \\
\hline Yes & $281(70.6)$ \\
\hline \multicolumn{2}{|l|}{ Place of care } \\
\hline Private service & $200(50.2)$ \\
\hline Public service & 198(49.8) \\
\hline \multicolumn{2}{|c|}{ It used dental health insurance } \\
\hline No & $310(77.9)$ \\
\hline Yes & $88(22.1)$ \\
\hline \multicolumn{2}{|c|}{ Reason for last dental care } \\
\hline Prevention & 155(38.9) \\
\hline Treatment & $243(61.1)$ \\
\hline
\end{tabular}


In the bivariate analysis, visiting the dentist in the last 6 months was significantly associated with gender ( $\mathrm{p}<0.001) ; 60.5 \%$ of those who sought service were females. History of toothache in life $(p=0.014)$ was also associated with visiting the dentist; $52.3 \%$ who sought the service presented this condition at some point in life. However, the only variable that remained significant in the multivariate model was gender $(\mathrm{p}<0.001)$, with prevalence ratio of 1.27 $(95 \% \mathrm{CI}=1.15-1.41)$ (Table 2$)$.

\section{Discussion}

Visiting the dentist regularly is essential for prevention and treatment of oral conditions in adolescence, which directly reflect in their quality of life. ${ }^{4,5,20}$ As most oral health-related outcomes, the hypothesis that sociodemographic and psychosocial variables predict dental visits is reasonable. An alarming frequency of dental anxiety and fear was found in this study, which might has severe consequences for the adolescentdentist relationship. However, these variables were not associated with visits to the dentist. Although gender was the only significant predictor for dental visits, the present findings are complex and the responsibility of the healthcare team to revert the situation are highlighted.

Most of the participants reported having visited general healthcare services in the last 6 months. On the other side, less than half accessed oral healthcare services in the same period. Probably, biological changes in this age group influence prioritization of general healthcare, while dental care is neglected or remain in the background. ${ }^{21}$ Most of the adolescents reporting dental visits at least once at some point in their life is not necessarily a positive result. The professional evaluation of oral health should be frequent to preserve, prevent, or treat oral conditions. The recommended longest interval between oral

Table 2. Bivariate and multivariate analysis through the Poisson regression in relation to the visit to the dentist in the last 6 months and its associated factors among adolescents of public schools. Campina Grande, Brazil.

\begin{tabular}{|c|c|c|c|c|c|c|}
\hline \multirow{3}{*}{ Variable } & \multicolumn{2}{|c|}{ Visit to the dentisit in the last 6 month } & \multirow{2}{*}{\multicolumn{2}{|c|}{$\begin{array}{c}\text { Bivariate } \\
\text { PR Unadjusted* }\end{array}$}} & \multirow{2}{*}{\multicolumn{2}{|c|}{$\begin{array}{c}\text { Multivariate } \\
\text { PR Adjusted** }\end{array}$}} \\
\hline & \multirow{2}{*}{$\begin{array}{c}\text { Yes } \\
n(\%)\end{array}$} & \multirow{2}{*}{$\begin{array}{c}\text { No } \\
n(\%)\end{array}$} & & & & \\
\hline & & & $\mathrm{p}$-value & $(95 \% \mathrm{Cl})$ & $\mathrm{p}$-value & $(95 \% \mathrm{Cl})$ \\
\hline \multicolumn{7}{|l|}{ Gender } \\
\hline Female & $135(60.5)$ & $88(39.5)$ & $<0.001$ & $1.28(1.16-1.40)$ & $<0.001$ & $1.27(1.15-1.41)$ \\
\hline Male & 77 (35.8) & $138(64.2)$ & & 1.00 & & 1.00 \\
\hline \multicolumn{7}{|c|}{ Age group (years) } \\
\hline $12-14$ & $64(44.8)$ & 79 (55.2) & & 1 & - & - \\
\hline 15-19 & $148(50.2)$ & $147(49.8)$ & 0.286 & $1.05(0.95-1.16)$ & - & - \\
\hline \multicolumn{7}{|c|}{ History of toothache in life } \\
\hline Yes & $148(52.3)$ & $135(47.7)$ & 0.014 & $1.13(1.02-1.25)$ & - & - \\
\hline No & $53(39.6)$ & $81(60.4)$ & & 1.00 & - & - \\
\hline \multicolumn{7}{|c|}{ History of toothache in the last 6 months } \\
\hline Yes & 65 (53.3) & $57(46.7)$ & 0.188 & $1.07(0.96-1.19)$ & - & - \\
\hline No & $133(46.2)$ & $155(53.8)$ & & 1.00 & - & - \\
\hline \multicolumn{7}{|l|}{ Anxiety } \\
\hline Yes & $22(47.8)$ & $24(52.2)$ & & 1 & - & - \\
\hline No & $190(54.0)$ & $162(46.0)$ & 0.432 & $1.06(0.91-1.24)$ & - & - \\
\hline \multicolumn{7}{|l|}{ Fear } \\
\hline Yes & $15(41.7)$ & $21(58.3)$ & & 1.00 & - & - \\
\hline No & $197(54.4)$ & $165(45.6)$ & 0.139 & $1.13(0.95-1.34)$ & - & - \\
\hline
\end{tabular}

*Poisson regression not adjusted for the independent variables and visit to the dentist in the last 6 months; ${ }^{*}$ Variables incorporated into the multivariate model $(p<0.20)$ : gender, history of toothache in life, history of toothache in the last 6 months and fear. 
health check-ups for patients younger than 18 years is 12 months. ${ }^{22}$ Healthcare teams should emphasize the importance as well as the frequency of dental visits. ${ }^{23}$ Educational interventions in schools with adolescents and parents/caregivers may be an efficient approach to increase awareness.

Most participants reported receiving treatment at the first visit to the dentist. However, it is important to reflect on this report, considering that private and public services where similarly accessed by adolescents. Despite the advances in Public Health Policies in Brazil, with the inclusion of Oral Health teams in the Family Health Strategy and the implementation of Dental Specialties' Centers, there are still gaps in the supply of these services for this group. Strategies that expand the access to oral healthcare services should be implemented, since the private sector is still responsible for a significant portion of these services in the country. ${ }^{24}$ In addition, $21.6 \%$ of adolescents had dental insurance, which reinforces the aforementioned assertion.

Preventive dental care leads to better oral health conditions and the avoidance of several diseases, such as dental caries and periodontal disease. ${ }^{25}$ In this study, the main aspect that motivated dental visits among adolescents was dental treatment. Some studies performed in richer regions of Brazil (i.e., south and southeast) found a higher prevalence of dental visits for routine consultation ${ }^{27}$ and other prevention procedures. ${ }^{1}$ Indeed, low socioeconomic status is a predictor of dental caries..$^{27}$ Therefore, the higher frequency of dental visits for treatment may be related to prevalence of oral conditions in regions with lower socioeconomic status.

The reason for females visiting the dentist more frequently than males might be due to the fact that women, since childhood, are more attentive with their health, seeking care more frequently. This trend occurs in most health specialties and may have cultural roots such as associating care seeking to a sign of "weakness", incompatible with masculinity. ${ }^{28}$

It is well known that feelings of fear and anxiety can prevent adolescents from seeking dental care, ${ }^{29}$ which are factors that lead patients to seek or delay dental treatment. ${ }^{30}$ Our results show that anxiety and fear are conditions that are still strongly present concerning dental care. Even with technological advances in dental procedures and equipment, patients still suffer from feelings of anxiety and fear, which affect comfort and wellbeing. However, these feelings are not exclusive of dental patients, but of all patients who undergo invasive treatments. ${ }^{31,32}$

This investigation had some usual limitations inherent to a cross-sectional study, which does not allow for the inference of causality, as exposures and outcomes are assessed simultaneously. Moreover, response bias related to the self-reported survey is possible. Based on the points made above, new hypotheses can be raised and explored. We suggest that future investigations include oral clinical outcomes for prediction of dental visits among adolescents. Besides, predictors in other age groups should also be explored to help establish public policies for a broader population.

Access to oral health services is considered a significant predictor of quality of life and should be verified and reflected for all age groups, including adolescents. ${ }^{33,34}$ A significant portion of this population still has difficulties accessing dental care services. Thus, the need for greater attention from the public administration towards young people is urgent in order to guarantee access to the public healthcare services.

\section{Conclusion}

The data allowed us to conclude that access to oral healthcare services reported by adolescents was good, but there is still a considerable part of this population with no access. Female sex and the history of toothache in life were the variables significantly associated with the seeking of dental services, but only female sex remained significant in the multivariate model.

\section{Acknowledgments}

This study was supported by the National Council for Scientific and Technological Development (CNPq) - No 22/2018, under grant No. 205043/2018-6, and financed in part by the Coordenação de Aperfeiçoamento de Pessoal de Nível Superior Brazil (CAPES) - Finance Code 001. 
Access to oral healthcare services of adolescents of a large-size municipality in northeastern Brazil

\section{References}

1. Ruzany MH, Andrade CL, Esteves MA, Pina MF, Szwarcwald CL. [Evaluation of operational conditions in the Adolescent Health Care Program, Rio de Janeiro]. Cad Saude Publica. 2002 May-Jun;18(3):639-49. Portuguese. https://doi.org/10.1590/S0102-311X2002000300008

2. Granville-Garcia AF, Fernandes LV, Farias TS, Bento PM, Medeiros CL, Menezes VA. Importance of oral health among adolescents in public schools of Campina Grande/PB, Brazil. Pesq Bras Odontoped Clin Integr. 2012 Sep;11(3):425-31. https://doi.org/10.4034/PBOCI.2011.113.18

3. Almeida TF, Cangussu MC, Chaves SC, Amorim TM. Oral health status of children, adolescents, and adults registered in Family Health Units Service in the Municipality of Salvador, State of Bahia, Brazil, in 2005. Epidemiol Serv Saude. 2012 Mar;21(1):109-18. https://doi.org/10.5123/S1679-49742012000100011

4. Feldens CA, Ardenghi TM, Dos Santos Dullius Al, Vargas-Ferreira F, Hernandez PA, Kramer PF. Clarifying the Impact of untreated and treated dental caries on oral health-related quality of life among adolescents. Caries Res. 2016;50(4):414-21. https://doi.org/10.1159/000447095

5. Colussi PR, Hugo FN, Muniz FW, Rösing CK. Oral health-related quality of life and associated factors in brazilian adolescents. Braz Dent J. 2017 Jan-Feb;28(1):113-20. https://doi.org/10.1590/0103-6440201701098

6. Pereira CR, Patrício AA, Araúio FA, Lucena EE, Lima KC, Roncalli AG. [Inclusion of oral health teams in the Family Health Program and its impact on the use of dental services]. Cad Saude Publica. 2009 May;25(5):985-96. Portuguese. https://doi.org/10.1590/S0102-311X2009000500005

7. Sanchez RM, Ciconelli RM. [The concepts of health access]. Rev Panam Salud Publica. 2012 Mar;31(3):260-8. Portuguese. https://doi.org/10.1590/S1020-49892012000300012

8. Martins MM, Aquino R, Pamponet ML, Pinto Junior EP, Amorim LD. [Adolescent and youth access to primary health care services in a city in the state of Bahia, Brazil]. Cad Saude Publica. 2019 Jan;35(1):e00044718. Portuguese. https://doi.org/10.1590/0102-311x00044718

9. Vazquez FL, Cortellazzi KL, Gonçalo CS, Bulgareli JV, Guerra LM, Tagliaferro ES, et al. Qualitative study on adolescents' reasons to non-adherence to dental treatment. Cien Saude Colet. 2015 Jul;20(7):2147-56. https://doi.org/10.1590/1413-81232015207.04502014

10. Costa AL Junior. [Psychology applied to pediatric dentistry: an introduction]. Estud Pesqui Psicol. 2013;2(2):46-53. Portuguese.

11. Gama TS, Oliveira CA, Cabral EL, Figueiredo HM, Guênes GM, Penha ES. Perfil do medo apresentado por crianças frente ao tratamento odontológico. Revista Unigá. 2017;29(3):23-7.

12. Costa AM, Terra JO, Souza SM, Terra FS, Freire GE. [Dental anxiety in high school students in Alfenas-MG]. Braz J Periodontol. 2014;24(2):13-8. Portuguese.

13. Teixeira AK, Roncalli AG, Noro LR. Factors related to the dental caries incidence in youth: a cohort study in Brazilian Northeastern. Cien Saude Colet. 2016 Dec;21(12):3871-8. https://doi.org/10.1590/1413-812320152112.12582015

14. Martins RJ, Belila NM, Garbin CA, Garbin AJ. [Fear and anxiety of students of different social classes when facing dental treatment]. Arch Health Invest. 2017;6(1):43-7. https://doi.org/10.21270/archi.v6i1.1785

15. Antunes JL, Peres MA, Frazão P. Cárie dentária. In: Antunes JLF, Peres MA, Epidemiologia da saúde bucal. Rio de Janeiro: Guanabara Koogan; 2006. p. 49-67.

16. Instituto Brasileiro de Geografia e Estatística - IBGE. Pesquisa Nacional por Amostra de Domicílios acesso e utilização de serviços de saúde. Brasília, DF, Instituto Brasileiro de Geografia e Estatística. 1998.

17. Kleinknecht RA, Klepac RK, Alexander LD. Origins and characteristics of fear of dentistry. J Am Dent Assoc. 1973 Apr;86(4):842-8. https://doi.org/10.14219/jada.archive.1973.0165

18. Corah NL, Gale EN, Illig SJ. Assessment of a dental anxiety scale. J Am Dent Assoc. 1978 Nov;97(5):816-9. https://doi.org/10.14219/jada.archive.1978.0394

19. Goes PS, Watt RG, Hardy R, Sheiham A. Impacts of dental pain on daily activities of adolescents aged 14-15 years and their families. Acta Odontol Scand. 2008 Feb;66(1):7-12. https://doi.org/10.1080/00016350701810633

20. Fonseca EP, Frias AC, Mialhe FL, Pereira AC, Meneghim MC. Factors associated with last dental visit or not to visit the dentist by Brazilian adolescents: A population-based study. PLoS One. 2017 Aug;12(8):e0183310. https://doi.org/10.1371/journal.pone.0183310

21. Coolidge T, Heima M, Johnson EK, Weinstein P. The Dental Neglect Scale in adolescents. BMC Oral Health. 2009 Jan;9(1):2. https://doi.org/10.1186/1472-6831-9-2

22. National Collaborating Centre for Acute Care. Dental recall: recall interval between routine dental examinations. London: National Collaborating Centre for Acute Care; 2004.

23. Coker TR, Sareen HG, Chung PJ, Kennedy DP, Weidmer BA, Schuster MA. Improving access to and utilization of adolescent preventive health care: the perspectives of adolescents and parents. J Adolesc Health. 2010 Aug;47(2):133-42. https://doi.org/10.1016/j.jadohealth.2010.01.005

24. Rocha RA, Goes PS. [Comparison of access to Oral Health Services between areas covered and not covered by the Family Health Program in Campina Grande, Paraíba State, Brazil]. Cad Saude Publica. 2008 Dec;24(12):2871-80. Portuguese. https://doi.org/10.1590/S0102-311X2008001200016

25. Thomson WM, Williams SM, Broadbent JM, Poulton R, Locker D. Long-term dental visiting patterns and adult oral health. J Dent Res. 2010 Mar;89(3):307-11. https://doi.org/10.1177/0022034509356779 
26. Lisbôa IC, Abegg C. Oral hygiene habits and use of dental services by adolescents and adults in the Municipality of Canoas, Rio Grande do Sul State, Brazil. Epidemiol Serv Saude. 2006;15(4):29-39. https://doi.org/10.5123/S1679-49742006000400004

27. Ortiz AS, Tomazoni F, Knorst JK, Ardenghi TM. Influence of socioeconomic inequalities on levels of dental caries in adolescents: a cohort study. Int J Paediatr Dent. 2020 Jan;30(1):42-9. https://doi.org/10.1111/ipd.12572

28. Meirelles RM, Hohl A. [Men's health: so neglected, mainly by men]. Arq Bras Endocrinol Metabol. 2009 Nov;53(8):899-900. Portuguese. https://doi.org/10.1590/S0004-27302009000800001

29. Noro LR, Roncalli AG, Mendes Júnior FI, Lima KC, Teixeira AK. Toothache and social and economic conditions among adolescents in Northeastern Brazil. Cien Saude Colet. 2014 Jan;19(1):105-13. https://doi.org/10.1590/1413-81232014191.2110

30. Josgrilberg EB, Cordeiro RCL. [Psycological management on children dental urgency treatment]. Odontol Clín-Cient. 2005;4(1):13-17. Portuguese.

31. Gonçalves KK, Silva JI, Gomes ET, Pinheiro LL, Figueiredo TR, Bezerra SM. Anxiety in the preoperative period of heart surgery. Rev Bras Enferm. 2016 Mar-Apr;69(2):397-403. https://doi.org/10.1590/0034-7167.2016690225i

32. Celik F, Edipoglu IS. Evaluation of preoperative anxiety and fear of anesthesia using APAIS score. Eur J Med Res. 2018 Sep;23(1):41. https://doi.org/10.1186/s40001-018-0339-4

33. Perazzo MF, Gomes MC, Neves ÉT, Martins CC, Paiva SM, Granville-Garcia AF. Oral health-related quality of life and sense of coherence regarding the use of dental services by preschool children. Int J Paediatr Dent. 2017 Sep;27(5):334-43. https://doi.org/10.1111/ipd.12266

34. Nazir MA. Patterns of dental visits and their predictors among male adolescents. Dent Med Probl. 2018 Apr-Jun;55(2):185-90. https://doi.org/10.17219/dmp/87023 